\title{
THE
}

\section{A Cross-Sectional Analysis of Perceptions of Interprofessional Education in Medical Students}

Nina Ayala

P. MacDonnell

University of Rhode Island, cmac@uri.edu

Luba Dumenco

Richard Dollase

Paul George

Follow this and additional works at: https://digitalcommons.uri.edu/php_facpubs

The University of Rhode Island Faculty have made this article openly available.

Please let us know how Open Access to this research benefits you.

This is a pre-publication author manuscript of the final, published article.

Terms of Use

This article is made available under the terms and conditions applicable towards Open Access Policy Articles, as set forth in our Terms of Use.

\section{Citation/Publisher Attribution}

Ayala, N., MacDonnell, C., Dumenco, L., Dollase, R., \& George P. (2014). A Cross-Sectional Analysis of Perceptions of Interprofessional Education in Medical Students. Annals of Behavioral Science and Medical Education, 20(2), 6-9. doi: 10.1007/BF03355285

Available at: http://dx.doi.org/10.1007/BF03355285 
Title: A Cross-Sectional Analysis of Perceptions of Interprofessional Education in Medical Students

Nina Ayala ScB1 ${ }^{1}$, Celia MacDonnell PharmD², Luba Dumenco MD¹, Richard Dollase EdD $^{1}$, Paul George MD MHPE ${ }^{1}$

${ }^{1}$ Alpert Medical School of Brown University, Providence, RI 02912

2 Department of Pharmacy Practice, University of Rhode Island, Kingston, RI 02881

Nina Ayala is a medical student in the Alpert Medical School of Brown University Class of 2014.

Celia MacDonnell is a Professor of Pharmacy at the University of Rhode Island.

Luba Dumenco is the Director of First Year Curriculum in the Office of Medical Education at the Alpert Medical School of Brown University.

Richard Dollase is the Director of the Office of Medical Education at the Alpert Medical School of Brown University

Paul George is the Director of Second Year Curriculum in the Office of Medical Education at the Alpert Medical School of Brown University.

Corresponding Author:

Paul George, MD MHPE

Alpert Medical School of Brown University

222 Richmond Street

Providence, RI 02912

Phone: 401-863-9609

Fax: 401-863-5711

Submission Date: March 7, 2014

Word Count: 1490

Financial Support: None

Previous Presentations: None

Conflict Disclosure: The authors report no conflicts of interest, financial or otherwise, in this study.

Key Words: Interprofessional education, interprofessional collaboration, undergraduate medical education 


\section{Abstract}

Title: A Cross-Sectional Analysis of Perceptions of Interprofessional Education in Medical Students

Background and Objectives: With the recent paradigm shift in medicine away from traditional hierarchies and patient-physician dyads, there is increased interest in training students to work interprofessionally. A primary focus for improving collaboration in health care is increasing exposure to formalized interprofessional education (IPE) across health professions during training. This study focuses on the effect of formal and informal curriculum on medical student attitudes towards IPE. Methods: A cross-sectional survey of all undergraduate medical students was conducted using the Readiness for Interprofessional Learning Scale (RIPLS). Results: Throughout all years of curriculum, students agreed with the importance of interprofessional education. Fourth-year medical students had higher total RIPLS scores than first years (61.0 versus 64.29; $\mathrm{p}=0.007$ ), as well as multiple individual RIPLS questions that were significantly higher.

Conclusions: Medical students become more enthusiastic about IPE as their training progresses; both formal and informal educational opportunities contribute to this effect. 


\section{Introduction:}

With rapid changes in healthcare delivery, there is a global shift away from the traditional patient-physician dyad into a more collaborative and team-oriented approach to patient care. It is almost uniformly posited that interprofessional collaborative care is the route to providing better patient-centered, efficient and cost-effective care. Numerous governing and policy-developing organizations focus on interprofessional collaboration (IPC) and learning as essential core competencies for healthcare trainees and a particular area for future healthcare innovation (1-3).

There is growing evidence that IPC improves staff communication and interactions as well as patient care outcomes $(2,4,5)$. As this teamwork-oriented paradigm for patient care is promoted and incorporated worldwide, questions still remain regarding how best to educate and train practitioners for this changing landscape. The answer to that question appears to be interprofessional education (IPE), defined as "two or more professions learn from, with and about each other to improve collaboration and quality of care" (3). Despite this emphasis on IPE as a mechanism to improve IPC, there has been minimal conclusive evidence tying improved clinical outcomes to IPE interventions $(4,6)$.

While many studies focus on interventions at the graduate or professional level, there has also been a significant increase in the incorporation of IPE at the undergraduate level with the intention to increase exposure to and communication with future partners during the most formative stages (7). The majority of these studies have focused on short-term interventions related to team building strategies and awareness of each student's prospective role in the healthcare team (7-14). 
Many others have focused on assessing the intersections between perceptions of IPE, professional identity and collaboration (15-21).

Despite medical students being partially or predominantly the subject of many of these studies, to our knowledge, no study to date has looked longitudinally at undergraduate medical students to determine whether perceptions toward other professions and IPC change throughout their training. This study examines whether students' attitudes towards IPE evolve over four years of undergraduate medical education.

\section{Methods:}

This study was conducted at a private medical school located in the northeast region of the United States. This study was exempted from IRB approval by the University review board.

The medical students at this institution participate in two required interprofessional education activities prior to graduation. The first, a workshop held early in second year, is previously described in detail elsewhere (8). Briefly, students in this workshop participate in introductory team building and patient case exercises. The second required educational activity, also a workshop, held at the beginning of third year, involves a team composed of one medical student, one nursing student, one pharmacy student and one social student. This workshop contains a standardized patient case, including a procedural component; participating in an advanced team building exercise (22) and brainstorming a solution to a complex ethical case. Each of the workshops is 3 hours in length. 
There is no other formal curriculum at our medical school in interprofessional education. In our study, the students in Year 1 functioned as a control group since they have not yet participated in an IPE workshop.

We hypothesized that these workshops would positively affect student perceptions of working interprofessionally and that that these perceptions would last longitudinally after these two required educational activities. It was determined that the Readiness for Interprofessional Learning Scale (RIPLS) was the most appropriate tool for data collection(23). All the subscale sections of the initially validated survey except for the "roles and responsibilities" section were distributed to all enrolled medical and completed on a voluntary basis. We omitted "the roles and responsibilities" questions secondary to space limitations on a larger survey.

We then performed an analysis of the data using SPSS Version 22 (2013, Chicago, IL). We looked first at descriptive statistics and calculated the total percentage of students responding to each of the questions on this scale. We then performed independent t-tests to identify differences in responses to questions between Year 1 students and Year 2 students (who had participated in one workshop). We performed the same analysis looking for differences between Year 2 students and a composite of Year 2/3/4 students (these students had all participated in at least one workshop), and eventually Year 2 compared to the Year 4 students.

\section{Results:}


The survey was distributed to a total of 460 medical students in Years 1 through 4 and we received 297 responses for a response rate of $64.6 \%$. The range of responses between classes was $52.4 \%$ for $3^{\text {rd }}$ years to $77 \%$ for $4^{\text {th }}$ years. Approximately $58 \%$ of the respondents were female and $42 \%$ were male.

69.0\% of all students reported prior experiences working interprofessionally during or prior to medical school. Of those that responded, $72.7 \%$ reported working with other professionals in a healthcare/or clinical setting; 75.6\% in a workshop and $76.1 \%$ working with a health care professional/non-physician. The degree of exposure to IPE differed greatly by class year with only $38.6 \%$ of students in Year 1 reporting prior experience with IPE. However by Year 4, 92.9\% of students reported experience in one or more of these settings.

Table 1 describes the responses to each of the questions on the RIPLS for the composite medical student body. There was a statistically significant difference between the Year 1 mean and the Year 4 mean for the total RIPLS score (61.0 versus 64.29; $\mathrm{p}=0.007)$. This difference disappeared when the Year 2 mean was compared to the Year 4 mean (64.18 versus $64.26 ; \mathrm{p}=0.91$ ). We noted no gender differences when evaluating total RIPLS score or individual question responses.

There was a statistically significant difference across 7 distinct questions when comparing Year 1 to the composite Year 2/3/4. This difference also disappeared when comparing Year 2 to the composite Year 2/3/4 values (Figure 2).

\section{Discussion:}

To our knowledge, this is the first study that has examined attitudes of medical students across all four years, and yielded important differences between 
our results and the existing literature on the subject. First, we did not detect any significant differences when stratifying for gender. Other authors have reported finding significantly higher scores in terms of perceptions of IPE/IPC in female students and professionals compared to their male counterparts, even leading some authors to label female professionals as "team players" $(11,18,20,24)$.

Additionally, researchers have previously reported that perceptions of IPE are initially very positive in nature, however, this idealistic view of IPE peaks early in the educational process and falls over time $(11,18,25)$. This was found to be contradictory to our results. Our data demonstrates that in our medical school setting, the lowest values both for individual questions and for the total RIPLS were in Year 1, increased predominantly between Year 1 and 2 and remained consistent throughout the remainder of medical school. Similarly, the changes in perceptions to individual RIPLS questions that were significantly different from first to fourth year spanned each of the subscales defined by Parsell and Bligh, demonstrating that the attitudinal changes were not specific to any one subset of interprofessional work or training. Of note, the only questions that were statistically significant when comparing Years 2 and 4 were within the 'effective team working' subscale (data not reported), demonstrating that there is room for improvement, particularly in that skillset during the clinical years, which in our institution occurs in a more organic way through interprofessional interactions and unofficial IPE while working on the wards.

It has been posited previously in other studies that it is important to allow students initially to develop a professional identity before introducing $\operatorname{IPE}(18,26)$. 
We agree that this is an important phase of professional training, and that once that identity is formed, earlier interprofessional interventions are valuable and produce the most effective and long lasting results. It is possible that these results differ significantly from previous findings because there is something intrinsically different about the medical school setting where our study took place either in the way that IPE is taught or in the type of student that is drawn to this community. However, we feel that our student population is overall representative of the average medical school population in the United States (27).

In conclusion, this is the first study to our knowledge that assesses medical student attitudes towards IPE over four years of medical education. This study lends credence to the concept that once students are introduced to IPE, their attitudes towards it and other health professions are positively affected. More importantly, this study demonstrates that the effect is not blunted with the absence of formal interprofessional curricular offerings in Years 3 and 4. Instead, organic IPE encounters, such as working on an inpatient team, may be sufficient to continue the positive attitude towards IPC for medical students.

Further studies are needed to show whether both formal and informal curricula in medical school affect the knowledge and skills of students working in health profession teams. However, we have demonstrated that formal and informal curricula do improve student attitudes towards IPC. 


\section{References:}

1. Accreditation Council for Graduate Medical Education standards for duty hours. Common program requirements. 2011.

2. World Health Organization. Framework for action on interprofessional education and collaborative practice. Geneva: World Health Organization. 2010.

3. CAIPE (Center for the Advancement of Interprofessional Education). Interprofessional Education. 2002.

4. Reeves S, Perrier L, Goldman J, Freeth D, Zwarenstein M. Interprofessional education: effects on professional practice and healthcare outcomes. Cochrane Database of Systematic Reviews. 2013(3).

5. Zwarenstein M, Reeves S. Knowledge translation and interprofessional collaboration: Where the rubber of evidence-based care hits the road of teamwork. J Contin Educ Health Prof. 2006;26(1):46-54.

6. Hallin K, Henriksson P, Dalen N, Kiessling A. Effects of interprofessional education on patient perceived quality of care. Med Teach. 2011;33(1):e22-6.

7. Pinto A, Lee S, Lombardo S, Salama M, Ellis S, Kay T, et al. The impact of structured inter-professional education on health care professional students' perceptions of collaboration in a clinical setting. Physiother Can. 2012;64(2):145-56.

8. MacDonnell C, Rege S, Misto K, Dollase R, George P. An introductory interprofessional exercise for healthcare students. Am J Pharm Educ. 2012;76(8).

9. Solomon P, Salfi J. Evaluation of an interprofessional education communication skills initiative. Education for Health. 2011;24(2). 
10. Morison S, Jenkins J. Sustained effects of interprofessional shared learning on student attitudes to communication and team working depend on shared learning opportunities on clinical placement as well as in the classroom. Med Teach. 2007;29(5):464-70.

11. Hansson A, Foldevi M, Mattsson B. Medical students' attitudes toward collaboration between doctors and nurses - a comparison between two Swedish universities. Journal of interprofessional care. 2010;24(3):242-50.

12. Hawkes G, Nunney I, Lindqvist S. Caring for attitudes as a means of caring for patients--improving medical, pharmacy and nursing students' attitudes to each other's professions by engaging them in interprofessional learning. Med Teach. 2013;35(7):e1302-8.

13. Curran V, Sargeant J, Hollet A. Evaluation of an interprofessional continuing professional development initiative in primary health care. J Contin Educ Health Prof. 2007;27(4):241-52.

14. Hallin K, Kiessling A, Waldner A, Henriksson P. Active interprofessional education in a patient based setting increases perceived collaborative and professional competence. Med Teach. 2009;31(2):151-7.

15. O'Neill BJ, Wyness MA. Student voices on an interprofessional course. Med Teach. 2005;27(5):433-8.

16. Neill M, Hayward KS, Peterson T. Students' perceptions of the interprofessional team in practice through the application of servant leadership principles. Journal of interprofessional care. 2007;21(4):425-32. 
17. Lumague M, Morgan A, Mak D, Hanna M, Kwong J, Cameron C, et al. Interprofessional education: the student perspective. Journal of interprofessional care. $2006 ; 20(3): 246-53$.

18. Coster S, Norman I, Murrells T, Kitchen S, Meerabeau E, Sooboodoo E, et al. Interprofessional attitudes amongst undergraduate students in the health professions: a longitudinal questionnaire survey. Int J Nurs Stud. 2008;45(11):166781.

19. Kvarnstrom S. Difficulties in collaboration: a critical incident study of interprofessional healthcare teamwork. Journal of interprofessional care. 2008;22(2):191-203.

20. Williams B, Boyle M, Brightwell R, McCall M, McMullen P, Munro G, et al. A cross-sectional study of paramedics' readiness for interprofessional learning and cooperation: results from five universities. Nurse Educ Today. 2013;33(11):1369-75.

21. Keshtkaran Z, Sharif F, Rambod M. Students' readiness for and perception of inter-professional learning: A cross-sectional study. Nurse Educ Today. 2013.

22. http://www.wilderdom.com/games/descriptions/Zoom.html. Accessed March 5, 2014.

23. Parsell G, Bligh J. The development of a questionnaire to assess the readiness of health care students for interprofessional learning (RIPLS). Med Educ. 1999;33:95-100.

24. Wilhelmsson M, Ponzer S, Dahlgren LO, Timpka T, Faresjo T. Are female students in general and nursing students more ready for teamwork and interprofessional collaboration in healthcare? BMC Med Educ. 2011;11:15. 
25. McFadyen AK, Webster VS, Maclaren WM, O'Neill M A. Interprofessional attitudes and perceptions: Results from a longitudinal controlled trial of preregistration health and social care students in Scotland. Journal of interprofessional care. $2010 ; 24(5): 549-64$.

26. Pirrie A, Wilson V, Harden RM, Elsegood J. AMEE guide no. 12: multiprofessional education: part 2-promoting cohesive practice in health care. Med Teach. 1998;20:409-16.

27. Mullan F, Chen C, Petterson S, Kolsky G, Spagnola M. The social mission of medical education: Ranking the schools. Ann Intern Med. 2010;152:804-11. 
Table 1: Descriptive Analysis of Composite Year 1-4 Responses to RIPLS Questions

\begin{tabular}{|c|c|c|c|c|c|}
\hline Question & $\begin{array}{c}\text { Strongly } \\
\text { Agree }\end{array}$ & Agree & Neutral & Disagree & $\begin{array}{l}\text { Strongly } \\
\text { Disagree }\end{array}$ \\
\hline $\begin{array}{l}\text { 1) Learning with other (HC S/P) will make me a more } \\
\text { effective member of a healthcare team }\end{array}$ & $60.6 \%$ & $36.4 \%$ & $3.0 \%$ & $0.0 \%$ & $0.0 \%$ \\
\hline $\begin{array}{l}\text { 2) Patients would be ultimate beneficiaries if HC S/P } \\
\text { worked together }\end{array}$ & $61.6 \%$ & $36.4 \%$ & $2.0 \%$ & $0.0 \%$ & $0.0 \%$ \\
\hline $\begin{array}{l}\text { 3) Shared learning with other HC S/P will increase my } \\
\text { ability to understand clinical problems }\end{array}$ & $45.8 \%$ & $43.1 \%$ & $9.0 \%$ & $2.0 \%$ & $0.0 \%$ \\
\hline $\begin{array}{l}\text { 4) Communication skills should be learned with other } \\
\text { HC S/P }\end{array}$ & $56.6 \%$ & $37.0 \%$ & $5.4 \%$ & $1.0 \%$ & $0.0 \%$ \\
\hline 5) Learning teamwork skills is vital for all HC S/P & $78.5 \%$ & $19.9 \%$ & $1.0 \%$ & $0.3 \%$ & $0.3 \%$ \\
\hline $\begin{array}{l}\text { 6) Shared learning will help me understand my own } \\
\text { personal limitations }\end{array}$ & $42.1 \%$ & $44.4 \%$ & $11.8 \%$ & $1.7 \%$ & $0.0 \%$ \\
\hline $\begin{array}{l}\text { 7) Learning that occurs between HC students would } \\
\text { improve working relationships during clinical practice }\end{array}$ & $49.2 \%$ & $40.4 \%$ & $9.4 \%$ & $1.0 \%$ & $0.0 \%$ \\
\hline $\begin{array}{l}\text { 8) Shared learning will help me think positively about } \\
\text { other HCP }\end{array}$ & $42.4 \%$ & $39.4 \%$ & $16.5 \%$ & $1.7 \%$ & $0.0 \%$ \\
\hline $\begin{array}{l}\text { 9) For small group learning to be effective, students } \\
\text { need to respect and trust each other }\end{array}$ & $60.9 \%$ & $36.0 \%$ & $1.7 \%$ & $1.3 \%$ & $0.0 \%$ \\
\hline $\begin{array}{l}\text { 10) I don't want to waste time learning with other HC } \\
\text { S/P }\end{array}$ & $1.3 \%$ & $1.7 \%$ & $8.4 \%$ & $54.9 \%$ & $33.7 \%$ \\
\hline $\begin{array}{l}\text { 11) It is not necessary for undergraduate or } \\
\text { postgraduate HC S/P to learn together }\end{array}$ & $1.7 \%$ & $5.1 \%$ & $14.8 \%$ & $52.2 \%$ & $26.3 \%$ \\
\hline $\begin{array}{l}\text { 12) Clinical problem solving can only be learned } \\
\text { effectively with HC S/P from my own school }\end{array}$ & $2.0 \%$ & $4.0 \%$ & $7.4 \%$ & $54.9 \%$ & $31.6 \%$ \\
\hline $\begin{array}{l}\text { 13) Shared learning with other HCP will help me to } \\
\text { communicate better with patients and other HCP }\end{array}$ & $39.1 \%$ & $51.2 \%$ & $8.1 \%$ & $1.3 \%$ & $0.3 \%$ \\
\hline $\begin{array}{l}\text { 14) I would welcome the opportunity to work on } \\
\text { small group projects with other HC S/P }\end{array}$ & $31.0 \%$ & $44.1 \%$ & $18.5 \%$ & $4.4 \%$ & $2.0 \%$ \\
\hline $\begin{array}{l}\text { 15) I would welcome the opportunity to share some } \\
\text { generic lectures, tutorials or workshops with other } \\
\text { HC S/P }\end{array}$ & $27.6 \%$ & $50.5 \%$ & $16.5 \%$ & $4.4 \%$ & $1.0 \%$ \\
\hline $\begin{array}{l}\text { 16) Shared learning and practice will help me clarify } \\
\text { the nature of patients' problems }\end{array}$ & $27.3 \%$ & $50.8 \%$ & $17.8 \%$ & $3.7 \%$ & $0.3 \%$ \\
\hline
\end{tabular}

${ }^{*} \mathrm{HC} \mathrm{S} / \mathrm{P}=$ healthcare students/professionals 


\section{Comparative Values of RIPLS Responses by Medical School Year}

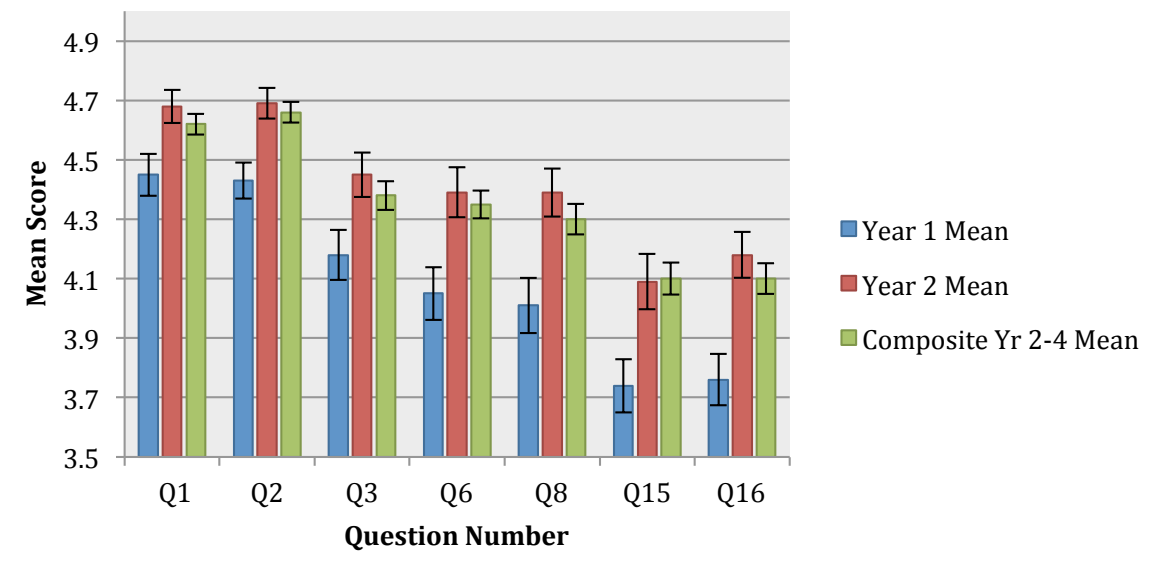

Figure 1: Demonstrates the seven questions that are significantly different between Year 1 and composite Year 2-4 means. That difference is maintained when Year 1 is compared to Year 2, suggesting that the most significant change in perceptions toward IPE occurs between Years 1 and 2.

Question key: Q1: Learning with other healthcare students/professionals (HC S/P) will make me a more effective HC team member. Q2: Patients would be ultimate beneficiaries if HC S/P worked together. Q3: Shared learning with other HC S/P will increase my ability to understand clinical problems. Q6: Shared learning will help me understand my own personal limitations. Q8: Shared learning will help me think positively about other HCP. Q15: I would welcome the opportunity to share some generic lectures, tutorials or workshops with other HC S/P. Q16: Shared learning and practice will help me clarify the nature of patients' problems. 